\title{
Biodiesel for Sustainable Energy Provision in Developing Countries
}

\author{
Moses Tunde Oladiran, Jerekias Gandure
}

Faculty of Engineering and Technology, University of Botswana, Gaborone, Botswana.

Email: oladiran@mopipi.ub.bw

Received May $4^{\text {th }}, 2011$; revised July $15^{\text {th }}, 2011$; accepted July $30^{\text {th }}, 2011$.

\begin{abstract}
Consumption of fossil fuel resources has been growing over the years and it is the kernel of economic development. However combustion which takes place principally in automobiles, power generation and industrial plants produces greenhouse gases (GHG) that are harmful to the environment. The release of GHG such as carbon dioxide is contributing to global warming. Biofuels can lower carbon footprint, reduce dependence on imported fossil fuels and increase energy security. Integrating biofuels into the national energy mix also has good socio-economic and sustainability potential. Therefore this paper discusses factors for successful diffusion of biodiesel technology in developing economies.
\end{abstract}

Keywords: Biodiesel, Developing Countries, Feedstock, Success Factors

\section{Introduction}

Availability of energy is essential for sustainable development. Nonrenewable energy resources are less attractive because of their finiteness, continuous price hikes, and environmental pollution from combustion processes. Many developing states are signatories to the United Nations Framework Convention on Climate Change (UNFCCC) and Kyoto Protocol. Therefore they are committed to lowering national carbon footprint by mitigating the amount of greenhouse gases $(\mathrm{GHG})$ such as $\mathrm{CO}_{2}$ produced from various thermal systems [1]. The combination of rising energy costs, insecure pathways of liquid energy carriers and increasing environmental pollution are motivating nations to develop and adopt indigenous, renewable and environmentally friendly fuels. Energy provision from renewable energy technologies (e.g. wind, solar and biofuels) is increasing on a large scale internationally.

Biofuels seem to be uniformly distributed globally. It was used during the industrial revolution (1750 to 1900). For example, Diesel used peanut oil to fuel the world's first compression ignition engine and he asserted in 1912 [2] that "the use of vegetable oils for engine fuels may seem insignificant today. But such oils may in the course of time become as important as petroleum and the coal tar products of present time".

Development and use of biodiesel has increased significantly especially since the first major oil price hike of the early 1970's. The European Union (EU) is the world's leader of biodiesel production. Figure 1 shows the ten top-ranked biodiesel producing countries in EU and they account for almost $90 \%$ of the Union's output [3]. The other main biodiesel producers are: North America (USA), Asia (India, Malaysia) and South America (Brazil).

Biofuels have become very appealing because of their potential to provide reliable and sustainable energy. International efforts, national strategies and local community involvement are being initiated or enhanced for biofuels production in several countries [4-9]. Many countries have good reserves of biofuels to make the resource attractive for transportation and power production. How-

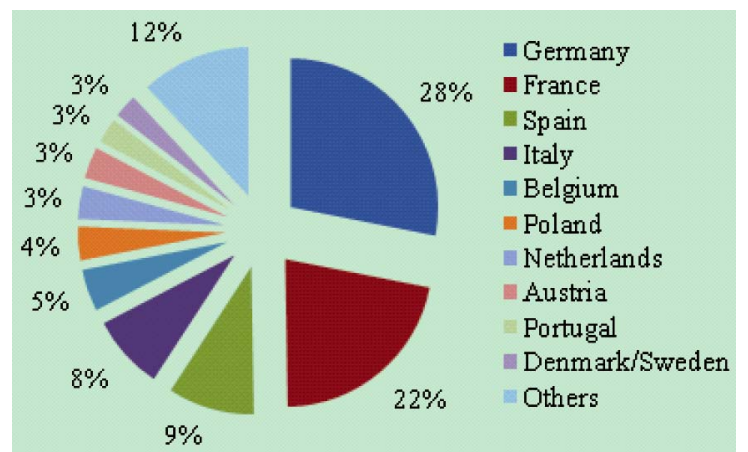

Figure 1. Ten (10) top EU producers of biodiesel adapted from [3]. 
ever in many developing countries e.g. in sub-Saharan Africa information on suitable land for biofuel projects is usually unavailable or scanty. In some nations such as Botswana land mapping has recently been undertaken to identify suitable land resource for biofuels development [10].

This paper therefore provides an assessment of resource availability, characteristics and challenges of biofuels production and its introduction into local energy markets. Factors for successful biodiesel adaptation and some plant technologies are also discussed. The study indicates that biofuels technology should be pragmatically and strategically incorporated into existing energy and fuel programmes, plans and policies.

\section{Biodiesel Characteristics}

\subsection{Chemical Production}

Biodiesel is an attractive alternative fuel for use in diesel engines. It is produced from a chemical process called transesterification. In the reaction a feedstock such as animal fat (tallow) or vegetable oil reacts with an alcohol (e.g. methanol or ethanol) and a catalyst (sodium or potassium hydroxide) to form monoalkyl methyl esters (biodiesel) of long chain fatty acids. Glycerin (glycerol) is a co-product of the transesterification process [11]. The reaction process is governed by the following chemical equation:

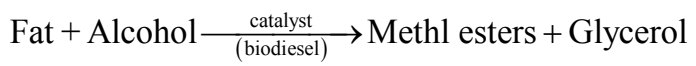

i.e.

Triglycerides $+3 \mathrm{ROH} \stackrel{\text { catalyst }}{\longrightarrow} 3 \mathrm{R}^{\prime} \mathrm{CO}_{2} \mathrm{R}+$ Glycerol

As esters (biodiesel) is less dense than glycerol, it floats on top of the glycerol. The biodiesel may be easily drained off or the glycerol can be pumped from the bottom of the reactor vessel. The biodiesel can then be cleaned-up in a purification process consisting of water washing, drying, and filtration to remove impurities such as soap, excess alcohol and catalyst.

Transesterification process is highly susceptible to formation of soap which reduces the throughput and quality of biodiesel. Therefore the efficiency of the process could be increased by eliminating (or significantly reducing) tendency to form soap as a byproduct. The quantity and quality of final biodiesel product depends principally on the type and composition of the initial feedstock, as well as on the reaction conversion and process separation efficiencies.

\subsection{Feedstocks}

A feedstock is the raw material from which oils and fats are derived for various applications (e.g. biodiesel proc- ess). The common vegetable oil feedstocks are rapeseed, soybean, cottonseed, linseed, and peanut. Other feedstocks for biodiesel production include waste vegetable oil (wvo), beef tallow or chicken fat. Used cooking oil is relatively cheap and abundant (e.g. from hotels and restaurants) for easy conversion into biodiesel. Collection of wvo can be a challenge in developing countries where biodiesel production relies on multiple small or medium wvo supplies which may be some distances apart. The quantity of polymers in wvo is a good measure of quality of biodiesel fuel.

Biofuels production in the EU is mainly from rapeseed. In Brazil, ethanol is from sugar cane; in Malaysia biodiesel is from palm oil, and USA uses mostly corn for ethanol production or soya bean for biodiesel. Investigation into use of jatropha oil is growing rapidly in several developing countries [6-9] e.g. India. There are other indigenous nonfood crops and plants that could be exploited for biofuel production. For example, many algal species that grow rapidly could yield oil for biodiesel production. Table 1 summarises active biofuel production and corresponding feedstocks in some developing countries [12]. The cost of biodiesel fuel is largely dependent on the choice of feedstock [13].

\subsection{Properties of Biodiesel}

Biodiesel must be tested to comply with international standards. The 2 most popular biodiesel standards in the world are the European (EN 14214) and the American Standard for Testing and Materials (ASTM D6751) standards. The standards are comparable and details of ASTM D6751 are shown in Table 2 [14]. The main tests that should be carried out are: kinematic viscosity, flash point, density, cloud point, and cetane number.

A maximum permissible glycerol concentration of $0.02 \%$ by weight is set by both the European standard and the ASTM specification. Therefore, it is necessary to determine the amount of free glycerol in biodiesel. Storage stability is another important characteristic of biodiesel as the fuel may stay for a long time before use either within the manufacturing site or at the end user's facility. Storage stability is an indication of property variability. Biodiesel has poor storage stability as it is susceptible to chemical attack under certain environmental or operational conditions. These chemical changes include oxidation due to contact with atmospheric oxygen.

Water in biodiesel could also contribute to hydrolysis and microbial growth that produces acidic fuel and sludges that could plug fuel filters. Some additives (such as antioxidant) could be added to enhance biodiesel storage stability. As a rule of thumb, biodiesel that would be stored or unused for more than 6 months should be 
Table 1. Production and feedstock in selected developing countries [12].

\begin{tabular}{|c|c|c|c|c|c|c|}
\hline \multirow[t]{2}{*}{ Country } & \multicolumn{3}{|c|}{ Ethanol } & \multicolumn{3}{|c|}{ Biodiesel } \\
\hline & Production (ML) & Typical use & $\begin{array}{l}\text { Feedstock } \\
\text { AFRICA }\end{array}$ & Production (ML) & Typical use & Feedstock \\
\hline South Africa & 416 & & Sugarcane & & B1-B3 by 2006 & Jatropha \\
\hline Malawi & 6 & Encouraging use & Sugarcane & & & \\
\hline Ghana & 6 & Encouraging use & Sugar, corn & & & \\
\hline Zimbabwe & 6 & & Sugarcane & & & \\
\hline Kenya & 3 & & Sugarcane & & & \\
\hline & & & ASIA & & & \\
\hline China & 3649 & $\begin{array}{l}\text { E10 but most not for } \\
\text { fuel }\end{array}$ & $\begin{array}{l}\text { Corn, cassava, } \\
\text { sugarcane, rice, } \\
\text { sweet potato }\end{array}$ & $\begin{array}{c}68 \mathrm{ML} \\
\text { (capacity 2004) }\end{array}$ & & $\begin{array}{l}\text { Jatropha and } \\
\text { others }\end{array}$ \\
\hline India & 1749 & E5 & Sugarcane & & B20 by 2011 & Jatropha \\
\hline Thailand & 280 & E10 & $\begin{array}{c}\text { Sugarcane, } \\
\text { tapioca/cassava } \\
\text { SOUTH AMERICA }\end{array}$ & $\begin{array}{l}90 \text { ML (2005). } \\
722 \mathrm{ML} \text { by } 2010\end{array}$ & & $\begin{array}{c}\text { Palm, soya peanut, } \\
\text { coconut, Jatropha }\end{array}$ \\
\hline Brazil & 15,098 & E26 & Sugarcane & Minimal & B2, B5 & $\begin{array}{c}\text { Soya oil, castor oil, } \\
\text { palm oil }\end{array}$ \\
\hline Colombia & 900 lt/day & E10 & Sugarcane & & B5 & Palm oil \\
\hline
\end{tabular}

"Bxx" and "Eyy" imply that the fuel contains xx \% and yy\% of biodiesel and ethanol respectively.

Table 2. Detailed requirements for biodiesel taken from ASTM D6751-09 [14].

\begin{tabular}{|c|c|c|c|}
\hline Property & Method & Limits & Units \\
\hline $\begin{array}{c}\text { Calcium and Magnesium, } \\
\text { combined }\end{array}$ & EN 14538 & $5 \max$ & $\operatorname{ppm}(\mu \mathrm{g} / \mathrm{g})$ \\
\hline Methanol content & EN 14110 & $0.2 \max$ & mass $\%$ \\
\hline Flash point & D 93 & $130 \mathrm{~min}$ & ${ }^{\circ} \mathrm{C}$ \\
\hline Water and sediment & D 2709 & $0.050 \max$ & $\%$ volume \\
\hline Kinematic viscosity, $40^{\circ} \mathrm{C}$ & D 445 & $1.9-6.0$ & $\mathrm{~mm}^{2} / \mathrm{s}$ \\
\hline Sulfated ash & D 874 & $0.020 \max$ & $\%$ mass \\
\hline Sulfur ${ }^{\mathbf{a}}$ & D 5453 & $0.0015 \max$ & $\%$ mass \\
\hline Copper strip corrosion & D 130 & No. 3 max & - \\
\hline Cetane number & D 613 & $47 \min$ & - \\
\hline Cloud point & D 2500 & Report & ${ }^{\circ} \mathrm{C}$ \\
\hline Carbon residue & D 4530 & $0.050 \max$ & $\%$ mass \\
\hline Acid number & D 664 & $0.50 \max$ & $\mathrm{mg} \mathrm{KOH} / \mathrm{gm}$ \\
\hline Free glycerin & D 6584 & $0.020 \max$ & $\%$ mass \\
\hline Total glycerin & D 6584 & $0.240 \max$ & $\%$ mass \\
\hline Phosphorus content & D 4951 & $0.001 \max$ & $\%$ mass \\
\hline Distillation temperature, T90 & D 1160 & $360 \max$ & ${ }^{\circ} \mathrm{C}$ \\
\hline Sodium and Potassium, combine & EN 14538 & $5 \max$ & $\operatorname{ppm}(\mu \mathrm{g} / \mathrm{g})$ \\
\hline Oxidation stability & EN 14112 & 3 minimum & hours \\
\hline
\end{tabular}

${ }^{\mathrm{a}}$ The specification also includes a higher sulfur grade of biodiesel, S500, that allows $0.05 \mathrm{wt} \%$ sulfur but all other requirements are identical.

treated with antioxidant additives [13].

Limited tests could be performed within a manufacturing facility but more sophisticated property tests could be outsourced to specialized professional laboratories.

\subsection{Advantages and Disadvantages of Using Biodiesel}

Adoption of biodiesel in the energy mix of several developing countries is based on its advantages including the following:

- Easy conversion process (production plant can be small, medium or large).

- Promotes energy security.

- Improves balance of payments i.e. reduces need to import petroleum oils and fuels.

- Creates new or additional jobs especially in rural communities to be engaged in feedstock production (e.g. jatropha plantation).

- Lowers greenhouse gas emissions.

- Enhances national export potential.

- Extends the life of diesel engines due to high lubricity.

- Requires minor or no modifications to the conventional compression ignition engines.

- $\quad$ Safe i.e. nontoxic, nonhazardous and biodegradable

- Renewable and clean burning.

- It has a high cetane number which is a measure of a fuel's ignition quality. For example, the high cetane number of biodiesel promotes easy cold starting.

- Glycerol which is the major byproduct of biodiesel production could be converted into propylene glycol and several other industrial chemicals.

Biodiesel can be used in engines and various manufacturing plants to replace fossil diesel fuel. It is also an 
attractive fuel for power plants or jet engines. The crude oil price may remain volatile (e.g. due to instability and crises in major oil producing regions) in the future which would promote use of alternative fuel supplies like biodiesel. New and commercial markets may be developed for agro-based crops associated with biodiesel production.

Despite the positive outlook for biodiesel it has some disadvantages such as:

- Lower energy content, higher viscosity, poor cold flow properties and lower volatility.

- Lower storage stability.

- Expensive feedstocks.

- Engine operation problems including fuel filter plugging, injector coking, and severe engine lubricant degradation.

\section{Blending}

Blending of biodiesel with fossil diesel is a common practice for various reasons. The blended fuel is referred to as "Bxx" which implies that the fuel contains $\mathrm{xx} \%$ of biodiesel. Thus a B5, B10, B20 or B100 fuel contains 5\%, $10 \%, 20 \%$ or $100 \%$ of biodiesel respectively. It is popular to use blended fuels varying between $2 \%$ and $20 \%$ although the latter limit is becoming more common. Adopting B100 would promote and create awareness locally for biodiesel as a unique fuel that can be used completely on its own.

There are several blending techniques and choice of an appropriate one must be based on good quality product, low operational cost, and simplicity of equipment. The commonest process is splash blending in which fossil diesel is poured into biodiesel in a tank or both fuels are poured simultaneously into a mixing chamber. Precautions must be taken to ensure thorough mixing without stratification in the vessel. The process can be assisted and enhanced by using mechanical mixers.

Other blending technologies include static, in-line, side stream, ratio, sequential and hybrid blending [13]. The blending process however has to be carried out with careful metering of the fuels for quality control purposes $[15,16]$. Blending is a secondary biodiesel process and could be performed in situ at the manufacturer's premise or at the end user's facility.

\section{Production Plant Technologies}

The engineering principles of the primary plant in a biodiesel production facility are well established. The equipment layout includes reactors, pumps, centrifuges, and distillation columns. There is also equipment such as settling chambers, storage tanks, pipe networks, valves, measuring instruments and other fittings.

Depending on the size and complexity of the infra- structure, a computer based system can be used to monitor plant performance. The selection of material for the construction of the reactor and storage tanks is an important consideration in production plant design. The technical demand on the materials used for storage tanks downstream of the reactor is lower since the tanks contain nearly $\mathrm{pH}$ neutral chemicals. In contrast, the materials required for the reactor must withstand basic conditions for transesterification reaction or acidic conditions if an esterification approach is used to convert free fatty acids. For the base-catalyzed transesterification reaction, stainless steel is the preferred material for the reactor [13].

However, in the acid-catalyzed esterification reaction stainless steel would not be appropriate because it is subject to attack by acids. Under these conditions, acid resistant materials such as Hastelloy should be used for the reaction vessel.

There are multiple operating options for making biodiesel e.g. batch and continuous processes. The technology of choice is a function of desired capacity, feedstock type and quality, and alcohol or catalyst recovery. The dominant factor in biodiesel production is the feedstock cost; capital costs may contribute only about $7 \%$ of the final product cost [13]. Some reaction systems are capable of handling a variety of feedstocks and qualities. Also, the various approaches to the esterification process imply different operating and water use requirements. In general, batch systems are attractive for smaller capacity plants and variable feedstock qualities. Continuous systems are common for operation on a $24 / 7$ basis but require large production volumes to justify huge investments. A more uniform feedstock quality is also essential for continuous production.

\section{Challenges of Biodiesel Technology Adoption}

As use of biodiesel increases it is likely that other secondary or parallel industries would evolve in developing nations [17]. The new industry would require design and manufacture of specialised equipment, facilities and control systems for downstream and upstream activities of the main biodiesel chemical plant.

Human resource gaps are a major challenge for the development, adoption and penetration of biofuels in most developing countries. However, in India there is a rapid growth in the level of awareness, research and government activities in agro - crops (e.g. Jatropha) for energy provision, employment creation and poverty alleviation in local communities $[6,18]$. Therefore it would be imperative for some of the education institutions to develop and offer new programmes in biodiesel and allied areas to produce human capital for the up-coming 
industry.

Population and urban migration would continue to increase in the next few decades in the developing countries. This would lead to increased energy consumption. As the bulk of energy supply is by thermal processes, $\mathrm{CO}_{2}$ generated per capita would grow steadily and environmental issues would increasingly be of concern. Therefore pressure on biodiesel production would increase in the coming years as a way of mitigating environmental pollution and global warming. However the demand for biodiesel may itself be sensitive to diesel price.

Renewable energy technologies would require some upfront public investment which should decrease as the level of technology adoption and use increases. For example, to be competitive, biodiesel needs subsidies from government. Such a need may conflict with governments' commitment to other public sectors such as health and education. However more national governments in developing countries are considering the use of public and private partnership (PPP) model to deliver projects. Sustained markets for biodiesel should grow by employing strong PPPs strategy.

Low or irregular rainfall could have devastating effect on energy crops e.g. jatropha. Also drought and diseases (such as foot and mouth disease) could affect the population of animals and invariably quality and quantity of animal fat and wastes available for transesterification reaction may be compromised.

Conflict of biofuels production with food crops could become a perennial issue if not properly managed. This is where land demarcation and what types of crops could be diverted to energy application is essential. For example South Africa banned use of maize/corn for biofuels production to reduce competition between energy and food crops. Therefore policies should be developed and monitored periodically for renewable energy technologies.

The role and coordination of small farmers could be a major challenge. The biodiesel producers need to optimize modern production processes and advances in research in their operations.

The major processing challenge is economics of the feedstock and other raw materials such as alcohol. Location of production plant must be thoroughly considered at the design stage to limit transportation cost and the rigour of collecting feedstock from various and sometimes distant places. The need and cost to carry out environmental impact assessment (EIA) and investigation could also be a challenge. However confidence in renewable technologies would be enhanced as EIA addresses sustainability issues.

\section{Key Success Factors for Biodiesel Programmes}

As shown in Figure 1, Germany is the principal biodiesel producer in EU and also in the world. A review of the experiences of that country could provide an understanding of issues for developing countries embarking on massive biodiesel projects [13]. The following key factors would be significant for successful introduction of biodiesel technology and plants in developing countries:

- Carry out research on various issues including feedstock resources, land usage and availability for planting jatropha and other agro-based energy crops, alternative feedstocks, manufacturing equipment suppliers, market and pump pricing.

- Create uninterrupted feedstock supply chain and management.

- Involve key stakeholders and investors from commencement of project to ensure buy-in and support

- Develop appropriate standards and guidelines (i.e. to cover production process, plant quality, feedstock, storage and final fuel dispensing) comparable to international benchmarks to guarantee confidence of local end users and regional markets.

- Emphasize and monitor quality of biodiesel products.

- Establish a marketing strategy to uniquely position biodiesel as an independent fuel and not a surrogate of the fossil fuel diesel. Modern blending practices can leave biodiesel in complete obscurity.

- Promote biodiesel at public gatherings and by using various media outlets.

- Develop long term strategy for progressive growth of biodiesel consumption in the overall national energy usage.

- Introduce incentive schemes (e.g. tax relief) for both manufacturers and end users to stimulate renewable energy market.

- Develop a political support motivated by the climate-change and sustainable development initiatives.

- Incorporate a glycerol purification and recovery system to produce high grade commercial glycerol.

- Design and use expandable production plant that is able to process different feedstocks.

- Co-ordinate jatropha farmers and provide modern breeding and seed production for outgrower schemes.

- Introduce attractive legislation and policies to favour biodiesel production i.e. create enabling environment for biodiesel to thrive.

In summary, there are many factors that can affect successful biodiesel project implementation. Some of these are: regular feedstock availability, appropriate site 
selection (e.g. optimum distance from feedstock supplier and market), incentives for consumers and investors, fuel quality, competitive prices, collaboration with stakeholders, aggressive market promotion, effective distribution channels, attractive guidelines and policy and flexible technology.

\section{Conclusions}

The technology for biodiesel production is simple and well established. The manufacturing plants can be of various sizes from small to complex facilities. The principal success factor for biodiesel production is availability of sustainable supply of raw materials. In particular as the biofuels industry emerges in developing countries, there would be a need for intensive research on biofuel resource potential and technologies to inform policy directions, land requirements and allocation, operating standards and procedures and investment opportunities. It would be necessary to consider sustainability issues (environmental, social and economic) at the start of biodiesel programmes so that policy can be reviewed or new ones instituted. Jatropha has been identified as a good material for biodiesel production in several developing countries but its effect on land and other native plants has to be established.

\section{REFERENCES}

[1] M. T. Oladiran, C. Kiravu and O. A. Plumb, "Assessment of Solar-Coal Hybrid Electricity Power Generating Systems," Proceedings of IASTED International Conference on Science \& Technology Applications for Health \& Sustainable Development, Gaborone, 6-8 September 2010.

[2] Jatropha, "The Next Big Revolution," 2010. http://jatropha- seeds.biz/fuels.html

[3] European Biodiesel Board, 2010. http://www.ebb-eu.org/ stats.php

[4] B. Amigun, R. Sigamoney and H. Von Blottnitz, "Commercialisation of Biofuel Industry in Africa: A Review," Vol. 12, No. 3, 2008, pp. 690-711.

[5] W. K. Biswas, P. Bryce and M. Diesendorf, "Model for Empowering Rural Poor through Renewable Energy Technologies in Bangladesh," Environmental Science and Policy, Vol. 4, No. 6, 2001, pp. 333-344. doi:10.1016/S1462-9011(01)00031-4

[6] G. Francis, R. Edigner and K. Becker, "A Concept for Simultaneous Wasteland Reclamation, Fuel Production, and Socio-Economic Development in Degraded Areas in India: Need, Potential and Perspectives of Jatropha Plantations," Natural Resources Forum, Vol. 29, No. 1, 2005, pp. 12-24. doi:10.1111-8947.2005.00109.x

[7] M. Benge, "Assessment of the Potential of Jatropha Curcas (Biodiesel Tree) for Energy Production and Other Uses in Developing Countries," 2006. http://www.echotech.org/ mambo/index.php

[8] M. Ye, C. Li, G. Francis and H. P. S. Makkar, "Current Situation and Prospects of Jatropha Curcas as a Multipurpose Tree in China," Agroforestry Systems, Vol. 76, No. 2, 2009, pp. 487-497. doi:10.1007/s10457-009-9226-X

[9] D. L. Kgathi, "Development of Jatropha Biofuel in Southern Africa," Proceedings of COMPETE International Workshop on Improved Energy Crop and Agroforestry Systems for Sustainable Development in Africa, Mauritius, 2007.

[10] EECG Consultants, "Feasibility Study for the Production and Use of Biofuels in Botswana," Final Report, Energy Affairs Department, Ministry of Minerals, Energy and Water Resources, Gaborone, 2007.

[11] P. Nakpong and S. Wootthikanokkhan, "High Free Fatty Acid Coconut Oil as a Potential Feedstock for Biodiesel Production in Thailand," Renewable Energy, Vol. 35, No. 8, 2010, pp. 1682-1687. doi:10.1016/j.renene.2009.12.004

[12] A. Dufey, "Biofuels Production, Trade and Sustainable Development: Emerging Issues,” 2006. http://www.iied. org/pubs/pdfs/15504IIED.pdf

[13] Future Fuels Africa, "Feasibility Study into the Establishment of Biodiesel Production in Lobatse," Final Report, Energy Affairs Department, Ministry of Minerals, Energy and Water Resources, Gaborone, 2010.

[14] ASTM D6751-09, "Standard Specification for Biodiesel Fuel Blend Stock (B100) for Middle Distillate Fuels (Diesel)." http://www.greenerpro.com/ASTM_D6751.html

[15] J. Gallehugh, "Biodiesel Blending Techniques Key to Quality Fuel," 2008. http://www.biodieselmagzine.com/article.jsp?article_id=2476

[16] J. Van Gerpen, "Biodiesel Processing and Production," Fuel Processing Technology, Vol. 86, No. 10, 2005, pp. 1097-1107. doi:10.1016/j.fuproc.2004.11.005

[17] F. Williams, "Biodiesel and Africa," 2006. http://www. steamautomobile.com/phorum5214/read.php

[18] Centre for Jatropha Promotion and Biodiesel, "Building a Sustainable Biodiesel Industry," 2010. http://www.jatro- phabiodiesel.org/ 